\title{
Creation of Blended Learning Environment
}

\author{
Choo-Kim Tan, Choo-Peng Tan, Shaun Ng Wes \\ Faculty of Information Science and Technology, Multimedia University, 75450 Melaka, Malaysia \\ Correspondence Author: Choo-Kim Tan, Faculty of Information Science and Technology, Multimedia University, 75450 Melaka, Malaysia
}

Received date: 15 August 2019, Accepted date: 30 September 2019, Online date: 28 October 2019

Copyright: (C) 2019 Choo-Kim Tan et al, This is an open-access article distributed under the terms of the Creative Commons Attribution License, which permits unrestricted use, distribution, and reproduction in any medium, provided the original author and source are credited.

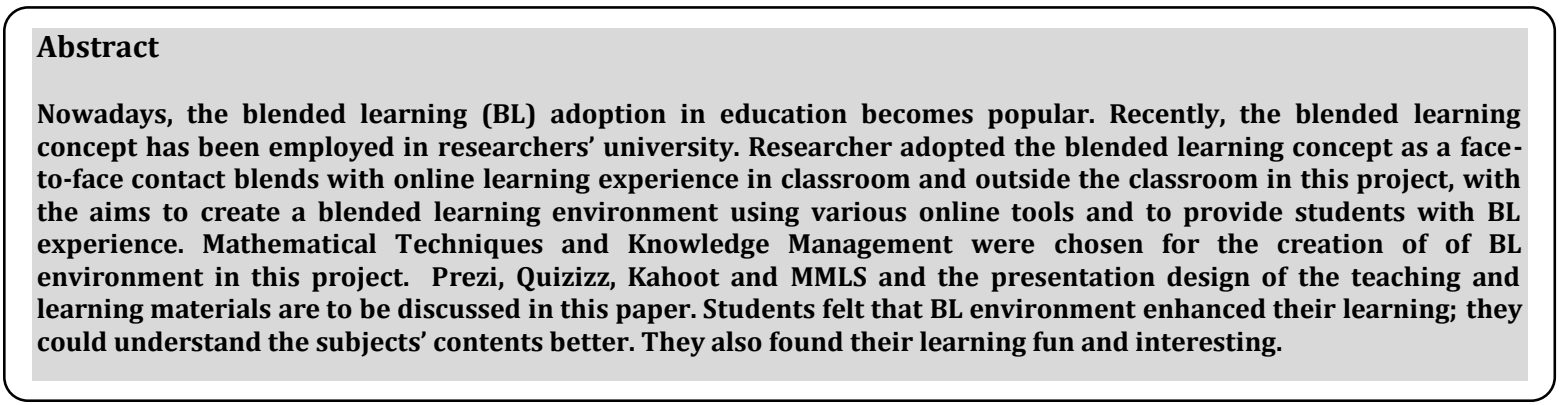

Keywords: Blended Learning, Environment, education

\section{INTRODUCTION}

The adoption of blended learning (BL) becomes popular in education nowadays. BL is not a new concept, but only the tools available for its implementation are new (Bersin, 2004). Bersin (2004) defined BL as the combination of different training "media" such as activities, technologies, and types of events for the creation of an optimum training program for a specific audience

However, it was found that there is no specific definition for BL. It can be defined in a broad spectrum or a very specific spectrum of learning experiences. The most common understanding on the term of BL is the combinations of any one or more teaching and learning approaches such as online learning with the face-to-face approaches. BL permits the interaction among the students and between the teacher and students (Ontario Ministry of Education, 2016).

Besides the conventional way of teaching, i.e. the face-to-face teaching and learning method, was conducted in classrooms in researchers' university previously, there was only one online system called Multimedia Learning System (MMLS) compulsory to be used for uploading the notes, tutorials, assignment, and etc. However, recently the BL concept was introduced in researcher's university. Hence, this project aimed to create a BL environment using various online tools and to provide students with BL experience.

\section{BLENDED LEARNING}

Griffith College (2017) stated that "blended learning is the integration of digital tools, techniques and materials with the physical classroom." BL is also referred to as a mixed, hybrid, or integrative learning method. The virtual learning environments (VLE) such as Moodle which uses online classrooms such as Zoom is adopted for BL implementation. In such environment, students learn, read, do assignments and raise questions online.

BL could be viewed as a flexible teaching and learning approach. It could be adopted with and/or without technologies and internet in the classrooms or computer lab. Online learning by accessing the course materials, answering questions, or doing assignments, etc. during the class can be done if the technologies and internet are available in the class or lab. In this case, teacher is the facilitator only. On the other hand, the face-to-face delivery by the teacher is to be conducted if the technologies and internet are not available in the class or lab, while the projects or assignments are to be completed at home and the submission is through online (Ontario Ministry of Education, 2016).

Allen et al. (2007) defined blended learning as a course blends online and face-to-face delivery. The online delivery is through a learning management system (LMS) or website. The LMS tools such as email, blog, quizzes, ePortfolio, calendar, 
Citation: Choo-Kim Tan, et al., Creation of Blended Learning Environment. Australian Journal of Basic and Applied Sciences, 13(10): 83-88. DOI: 10.22587/ajbas.2019.13.10.11

dropbox, etc. are supporting tools for face-to-face learning in which students could access the learning materials, assignments, etc. during the class or at home (Allen et al. 2007).

BL provides benefits in education and provides innovative ways of teaching and learning to students and educators. There was a study showed that the adoption of BL gives positive impact in reducing students' dropout rates and in improving their academic performance (López-Pérez et al., 2011).

According to Bailey et al. (2013), there are ten drivers of BL:

1. Improve ability to personalize learning

2. Potential to extend the reach of effective teachers

3. Potential for individual progress

4. Ability to improve working conditions

5. Improve student engagement and motivation

6. Decrease devise costs

7. Shift to online state tests

8. Student and parent adoption of learning apps

9. Need to extend time and stretch resources

10. Interest in narrowing the digital divide

Teachers involved in a study of Jeffrey et al. (2014) found that the online component in the BL reducing some of their administration load. In addition, in Jeffrey et al. (2014) study, online quizzes were used in four of the courses and it was found that these quizzes generated higher levels of engagement. Moreover, personal monitoring of students' engagement online was actively done by teachers through email by asking the students on any problem they faced as well as the help that they could provide to students. Consequently, it was found that the dropout rates for these courses were very low. Furthermore, students found learning is important now as they found that it helped them attain their personal goals.

The BL classroom is found not only benefits the students in general, but it also provides benefits to special education students. It is evident in Rivera's (2017) study that blended learning classroom provided a constructive and enriching learning experience to the special education students.

\section{BLENDED LEARNING CONCEPT}

In this project, two courses, i.e. Mathematical Techniques (MT) and Knowledge Management (KM) were chosen for the implementation of BL.

The BL concept in this project is the face-to-face contact blends with an online learning experience in classroom and outside the classroom. The selected tools for online learning are Prezi, Quizizz, Kahoot and MMLS. Some teaching materials were delivered through face-to-face classroom by the lecturers and some were using the tools. In addition, some quizzes and assignments were conducted online.

Prezi is a one-of-a-kind open canvas (a blank workspace) that allows the user creates, organizes, views and stores the presentation as a whole with its zooming editor tool. Thus, the storyboard is preparing in either a linear or free-flowing storyline depends on user's preference rather than in a fix linear storyline as in traditional presentation software. It has the capability to integrate text, images, audio, video and animation in a single presentation too. Its "Smart Structure" allows the arrangement of content easily by a simple drag-and-drop. The Zoom Reveal function allows users to focus on and unveil critical details as the story unfolds. Prezi permits free movement in which users navigate the presentation freely and easily without searching through slides for the topic that they want. There are over a hundred of templates made for every need with beautiful colours, sleek fonts, and gorgeous graphics to ease the user to create or to customize the stunning presentations. User may present the presentation online or offline or save a copy of the presentation as pdf file or share the presentation on Facebook. Also, user may share the presentation with his peers in Prezi to collaboratively edit the presentation slides online (n.d.).

In this project, Prezi was used to create the teaching and learning contents. After created the contents, the link was shared with students in order for them to experience their learning online. The contents were arranged in the sequences that students can follow, in which this would give students overall picture of the course content that they learn and enhance their understanding. It could be considered as one of the advantages of using Prezi. As shown in Figure 1, the 5 topics were created using the chosen template in Prezi Next. Students were first introduced to the 5 topics in the overview page. As the presentation goes on, the first topic, i.e. Vectors, is displayed with its subtopics (i.e. Dot Product, Cross product and Equations under the topic of Vectors) as shown in Figure 2. Then for each subtopic, the presentation is further displayed for its subtopic like the sample shown in Figure 3 for Equations. Further presentation is displayed for the subtopics for Equations as shown in Figure 4. The zoom function was used to make students focus on the formula or to emphasize the important points (Figure 5). The same presentation flow goes for the following topic until the last topic. Background music was inserted to make the learning environment interesting and voice was incorporated for explanation to enhance students' understanding.

Quizizz is an online tool for instructors to create quizzes either to create his own questions or to import the questions from all public quizzes created by other Quizizz users (n.d.). A quiz can be conducted as "PLAY LIVE!" or as "HOMEWORK". "PLAY LIVE!" mode is normally conducted in classroom. All learners are to present and take the quiz together. "HOMEWORK" mode is conducted in situations where all students are not able to take the quiz at the same time or as desired by instructor to give the exam 
as homework. Thus, instructor may have to set a deadline which could be 15 days from the starts besides all the settings as in "PLAY LIVE!" mode. Therefore, learners may attempt the quiz at their own pace within the timeline given. Once the quiz is finished, instructors will get the reports and progress of the quiz under "My Reports". The report in Excel can be downloaded under "My Reports".



Figure 1: Overview Page

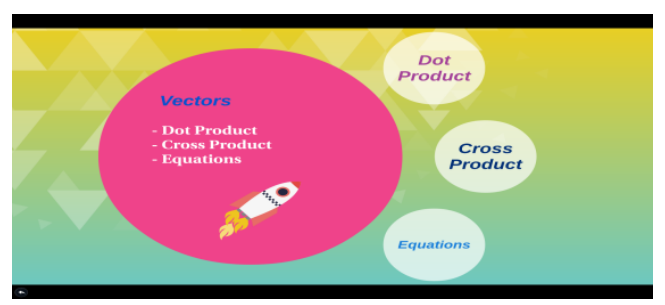

Figure 2: Fisrt Topic with Subtopics

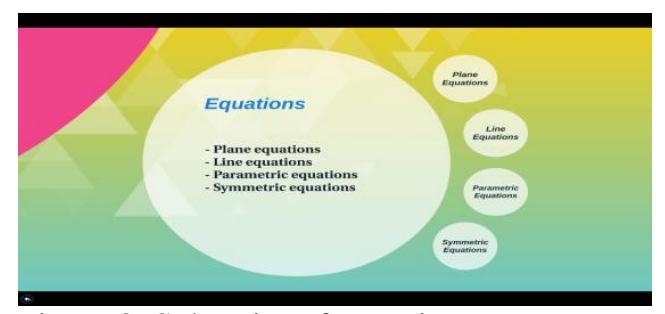

Figure 3: Subtopics of Equations



Figure 4: Subtopic for Equations

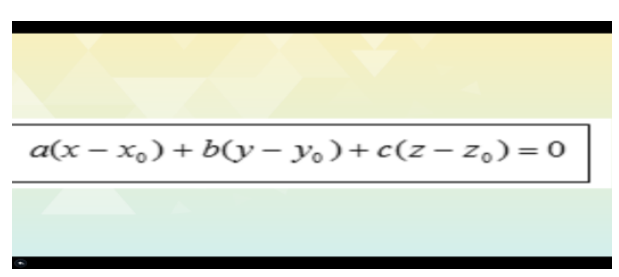

Figure 5: Zoom on the Formula

In this project, quizzes were designed using Quizizz in which both modes were employed. Figure 6 shows the quiz questions for KM which can be given to students using both modes. Students connected to Quizizz session at join.quizizz.com by entering the game code and their name (nickname or student ID) using their own portable devices and browser. Figure 7 shows the game code that was generated in Quizizz for students to attempt KM quiz questions. The lecturer checked on his own device if all students are connected to the quiz and he clicked "Start Game" button. The game code was only active for few hours. The students read the questions and answered along with the multiple-choice options one after another on their own devices. The lecturer got a live dashboard which will update automatically as students respond to questions. After the quiz was completed by students, a report in Excel was downloaded (Figure 7) and viewed by the lecturer to check each student's performance on which question he answered correctly, incorrectly and did not attempt (Figure 8). Hence, from this report, personal monitoring to those weak students was done and follow-up coaching was given to them to increase their understanding.

Kahoot! is another tool used in this project. It is a tool that enables teachers to create or to share fun learning games (multiple choice questions) called Kahoots with no limited format and number of questions. Instructors may add diagrams, images and videos to the questions to amplify learners' engagement. Kahoot! Is played in a group setting or a classroom (n.d.). 


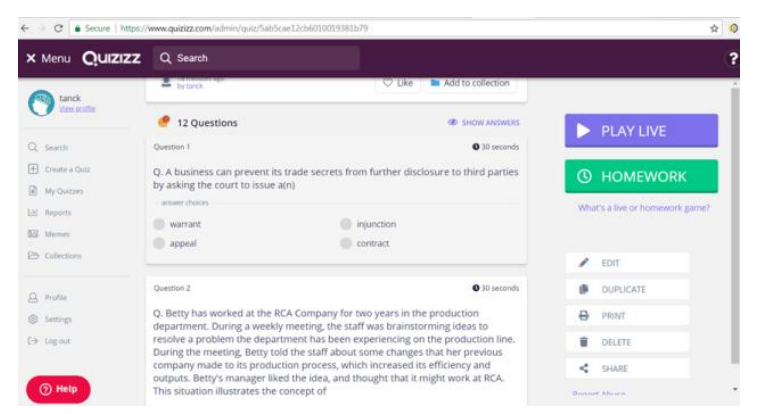

Figure 6: KM Quiz Questions

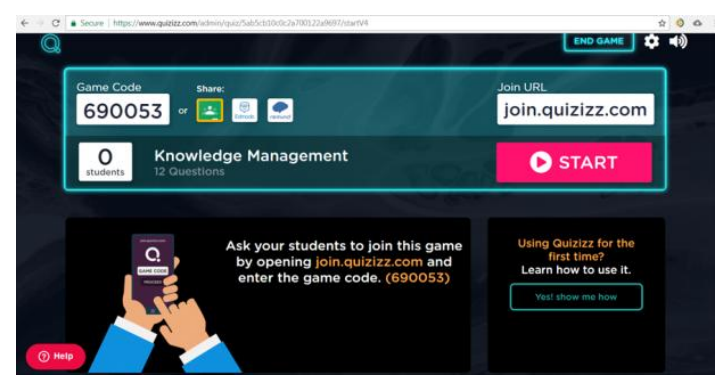

Figure 7: Game Code in Quizizz

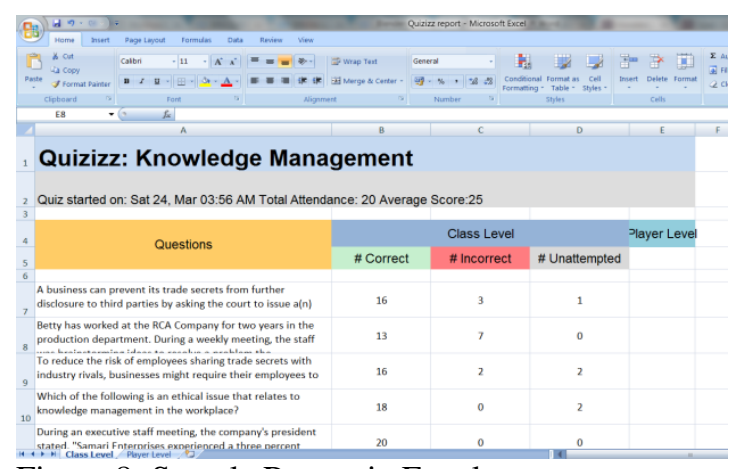

Figure 8: Sample Report in Excel

In this project, Kahoot! was used to create games. The purpose was to encourage participation and competition in class. It was conducted in the classroom after the face-to-face teaching by the lecturer. The time limit for each question was set. The lecturer launched Kahoot! in a web browser and displayed it on a shared screen (or through a projector) with a game pin (Figure 9). The students joined the game by entering the game pin and nickname at the URL kahoot.it in a web browser on their own portable devices without having an account in Kahoot!. The question together with the multiple-choice answers was displayed one after another on the shared screen after all students have hit the same color and symbol as the answer of each question on their own devices (Figure 10). A countdown timer and number of students who have submitted the answer were shown on the shared screen. While the game was carrying, a playful graphical user interfaces together with music and sounds were being used to create a playful and competitive atmosphere. Thus, "it creates a 'campfire moment' encouraging players to look up and celebrate together" as described by Kahoot!" on its website (n.d.). When the time is finished, the correct answer was ticked on the lecturer screen as shown in Figure 10 where the correct answer was ticked for a KM question. The score after answering each question (Figure 11) and the result after completing a game (Figure 12) were displayed.

Another tool for the BL of this project is MMLS, a system owned by the researchers' university. It is a web-based courseware delivery engine that utilizes multimedia to enhance the teaching and learning process, with a 'virtual teacher within a virtual classroom' (Nurhayati et al., 2002). It allows interaction between the instructor and the system and with students, and vice versa, with the aim to engage students in learning, hence to captivate and retain students' interest. The first prototype of MMLS was used in 1997 with limited features. The latest version of MMLS (i.e. 2017 version) allows lecturers to upload course outline, lecture notes, tutorial questions, announcement, quizzes etc. as well as to have a discussion online and chat as shown in Figure 13. The time limit or expiry date could be set for students to access each component in MMLS. 


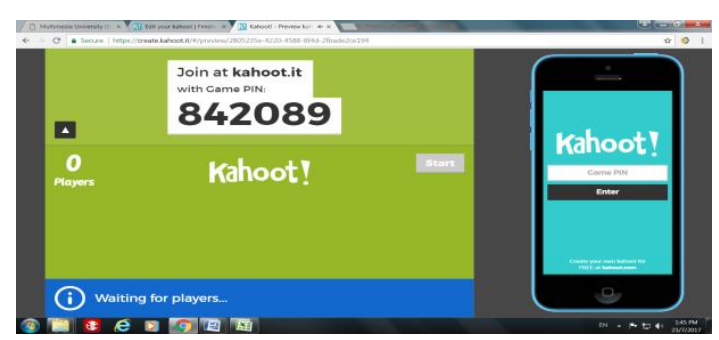

Figure 9: Game Pin in Kahoot!

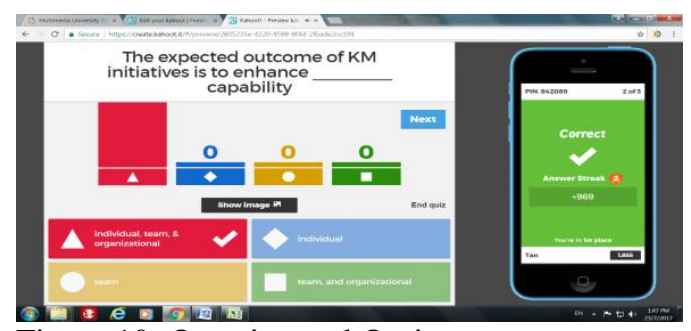

Figure 10: Question and Options

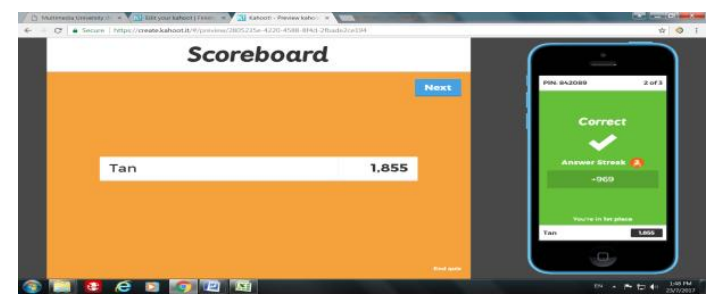

Figure 11: Score After Answering a Question

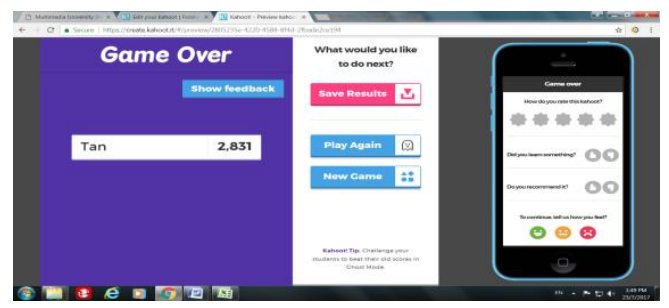

Figure 12: Result of a Game

Besides the lecture notes, tutorial questions and assignment in the pdf or Microsoft files were uploaded for students (Figure 14) in this project, the youtube videos links were shared in the announcement. Students can print or download all the files and watch the videos at anytime they want. All these components are viewable by students at the time frame set by lecturers, normally is at the end of the semester. However, the videos links were shared before the topic is taught in class. Students must watch the videos at home and the discussion on that topic would be carried out in the classroom. For example, if Differentiation topic will be taught in Week 5, then students must watch the video on this topic in Week 4 as the link was shared started from Week 4 and expired at the end of the semester. After watching the videos at home by students, it followed by the discussion in classroom. The discussion and problem-solving were done among the students. The lecturer was the facilitator and he guided the students if they face difficulty in solving the questions.



Figure 13: Multimedia Learning System 


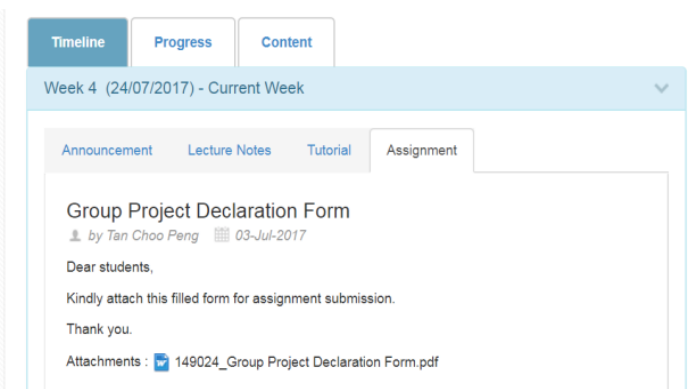

Figure 14: Page for Uploading Announcement, Lecture Notes, Tutorial and Assignment

Hence, the face-to-face classroom blended with MMLS encouraged interaction among students and with a lecturer. Furthermore, besides reading the hardcopy of lecture notes and listening to the lectures by the lecturer, students' understanding in the course was further enhanced with the videos and discussion.

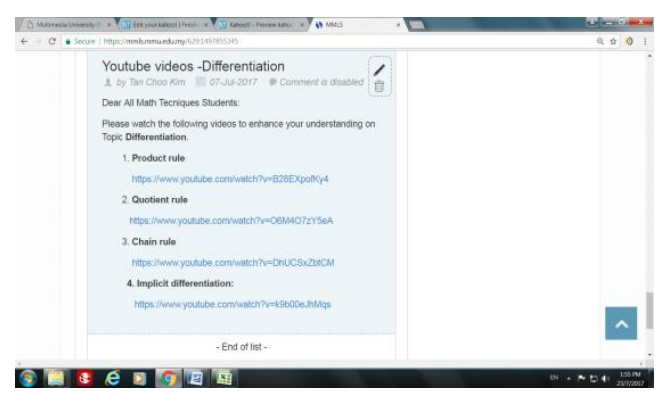

Figure 15: Youtube Videos Link in Announcement

\section{CONCLUSION}

The BL environment in this project provided an online learning experience to students on top of the face-to-face classroom experience that they are bored with. It is a new teaching and learning concept introduced to our students. Various online tools blended with face-to-face learning either in the classroom or outside the classroom had encouraged interaction and provided fun to students. Students of both courses, MT and KM, felt that BL environment enhanced their learning; they could understand the subjects' contents better. They also found their learning fun and interesting. Further research is to be conducted soon to gather students' views and feedback on each tool and their perceptions toward adoption of blended learning.

\section{ACKNOWLEDGEMENT}

We would like to thank Prezi.com, Quizizz.com, Kahoot.com and Multimedia University for their tools/systems to support the blended learning concept of this project.

\section{REFERENCES}

Allen, I.E., J. Seaman and R. Garrett, 2007. Blending in: The extent and promise of blended education in the United States. Sloan-C, Needham, MA.

Bailey, J., S. Ellis, C. Schneider and T. V. Ark, 2013. Blended Learning Implementation Guide. Retrieved from https://net.educause.edu/ir/library/pdf/CSD6190.pdf. on June 2017.

Bersin, J. , 2004. The Blended Learning Book: Best Practices, Proven Methodologies, and Lessons Learned. John Wiley \& Sons.

Griffith College, 2017. What is blended learning? Retrieved from https://www.griffith.ie/admissions/blended-onlinelearning/what-blended-learning/ on December 2017.

https://prezi.com/ (n.d.)

https://quizizz.com/ (n.d.)

https://kahoot.com/what-is-kahoot/ (n.d.)

Jeffrey, L. M., J. Milne, G. Suddaby and A. Higgins, 2014. Blended Learning: How Teachers Balance the Blend of Online and Classroom Components. Journal of Information Technology Education: Research, 13: 121-140.

López-Pérez, M. V., M.C. Pérez-López and L. Rodríguez-Ariza, 2011. Blended learning in higher education: Students' perceptions and their relation to outcomes. Computers \& Education, 56 (3): 818-826.

Nurhayati, Y., B. Madhubala, S. Fadzilah, and C.K. Tan, 2002. Multimedia Learning System. In the Proceedings of Information Technology and Universities in Asia: An International Conference. Chulalongkorn University, Bangkok, Thai.

Ontario Ministry of Education, 2006. E-Learning Ontario: Blended learning.

Rivera, R.H., 2017. The Blended Learning Environment: A Viable Alternative for Special Needs Students. Journal of Education and Training Studies, 5(2): 79-84. 